\title{
Comparison and Speed Control of DC Motor and DC Servomotor Using IMC Based PID Controller
}

Amarapini Divya ${ }^{1} \mid$ Dr.Prasadarao Bobbili ${ }^{2}$

${ }^{1}$ Department of EEE, Vignan's Institute of Information and Technology(A),Visakhapatnam

2Department of EEE, Vignan's Institute of Information and Technology(A), Visakhapatnam

To Cite this Article

Amarapini Divya and Dr.Prasadarao Bobbili, "Comparison and Speed Control of DC Motor and DC Servomotor Using IMC Based PID Controller", International Journal for Modern Trends in Science and Technology, 6(12): 493-501, 2020.

\section{Article Info}

Received on 16-November-2020, Revised on 09-December-2020, Accepted on 12-December-2020, Published on 21-December-2020.

\section{ABSTRACT}

IMC based PID controllers are being used to speed control of DC motor and DC servomotor in industry. As this controller offer good performance comparitive to conventional controllers like PI, PID and Ziegler Nichols frequency method controllers. This paper presents the speed control of the DC motor and DC servomotor using PI, PID, Ziegler Nichols method and IMC-PID controllers, to realize the optimization of control action. A mathematical calculation of DC motor and DC servomotor has developed and simulations are carried out in MATLAB/ Simulink environment.

From the results, it is observed that time domain parameters like rise time 0.6 secs, settling time 2 secs, speed for peak over shoot 1450, peak amplitude 1, with no oscillations using IMC-PID controller on DC motor. And for DC servomotor its rise time is 0.3 seconds, settling time is 1 second, speed for peak overshoot 1450 rpm, peak amplitude 1 with absence of oscillations by using IMC-PID controller

KEYWORDS:DC motor, DC servomotor, IMC based PID controller, PI controller, PID controller, Ziegler-Nichols controller.

\section{INTRODUCTION}

One of the most widely used industrial applications is DC motor, because of low cost, its high reliability, and its high flexibility. These DC motors are mostly in robot manipulators, home appliances, including conveyors, cranes, vaccum cleaner, sewing machine and others for which adjustable speed are required with constant or low speed torque are needed .

DC motors can converts its electrical energy into mechanical energy where the interaction of two magnetic fields, which one of its field that is produced by a magnet of poles assembly, and other field which is produced by an electrical current flowing in the motor windings. These two fields result in a torque which tends to rotate the rotor[5].

One of its advantage of DC motor is it control speed over a wide range of both and above its rated speed, it has large starting torque and best suited for electric traction and free from harmonics. The disadvantage is it has high initial cost, cannot operate in explosive and hazard conditions.

The DC Servomotors are commonly used for high technology devices in industrial applications like 
automatic technology. It is usually like a transducer that can convert electrical form of energy in to mechanical energy. A servomotor is rotary actuator or linear actuator that allows for actual control of linear position and speed control. The torque developed on shaft of the motor is directly proportional to field flux and armature current.

The heart of many control systems which are automatic in nature is servo motor drive. DC servomotor is treated as heart of the industrial applications. They are widely used in conveyor belts, radars, camera auto focus, solar tracking system and precise control applications. The DC servomotors are very expensive compared with AC servomotor because of its brushes and commutators . Usually, servos can operate in negative feedback, where control input is compared with actual position of the system by some sort of transducer at the output [1].

Any electrical motor can be utilized as servomotor if it is controlled by servomechanism. Although servomotors are not in a specific class of motor, they are proposed and designed to use in a motion control applications which is required for high accuracy positioning, quick reversing and exceptional performance. DC servomotors are used as simple applications because of their low cost, high efficiency and simplicity.

\section{WORKING OF DC MOTOR}

In this work, performance of DC motor and DC servomotor is observed in Simulink / MATLAB environment. For performing the operation of DC motor and DC servomotor, modelling of the motor is done in this work. These two motors is simulated under different conventional controllers. For PI-controller, steady state error of the system is reduced but less stable. For PID-controller, rise time and steady state error are controlled. Here uncontrolled parameter is overshoot. But in IMC design PID is tuned then rise time, steady state error, settling time are controlled along with peak overshoot.

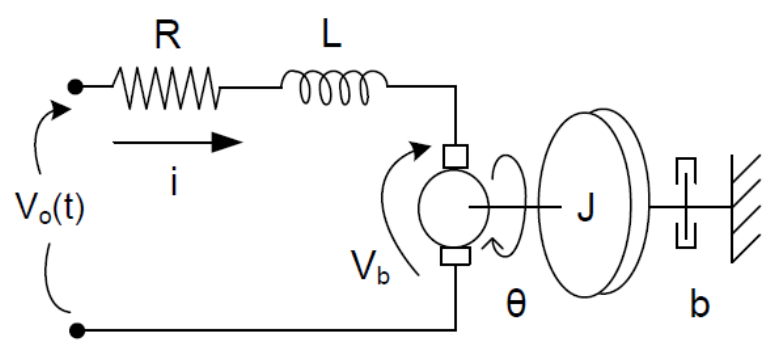

The armature voltage is given as,

$$
V_{\mathrm{a}}(t)=R_{a} \cdot I_{a}(t)+L_{a} \cdot \frac{d I a}{d t}+E_{b}(t)
$$

Equation for back emf of motor

$$
E_{b}(t)=K_{b} w(t)
$$

Torque equation will be

$$
T_{m}(t)=J \frac{d w(t)}{d t}+B w(t)
$$

Where $K_{t}=J \frac{d w(t)}{d t}+B w(t)$

Combine above equations

$$
V_{a}(t)=R_{a} \cdot I_{a}(t)+L_{a} \cdot \frac{d I a}{d t}+K_{b} w(t)
$$

Taking Laplace Transform of (5), we get

$$
\begin{aligned}
& V a(s)=R_{a} . I_{a}(\mathrm{~s})+L_{a} . I_{a}(\mathrm{~s})+K_{b} w(\mathrm{~s}) \\
& K_{t .} I_{a}(\mathrm{~s})=J w(\mathrm{~s})+B w(\mathrm{~s})
\end{aligned}
$$

Current equation is obtained from above two equation

So, the relation between speed of rotor shaft and armature voltage which is applied is given by transfer function.

$$
\frac{W(s)}{V_{a}(s)}=\frac{K_{t}}{\left.\left(U L_{a} s^{2}+\left(J R_{a}+B L_{a}\right) s+\left(K_{t} K_{b}\right)+B R_{a}\right)\right)}(8)
$$

This is transfer function of DC motor.

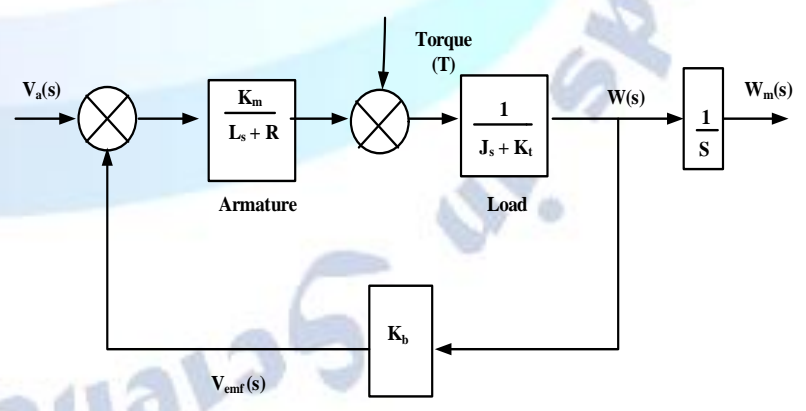

Fig.2. Block diagram of DC motor.

\section{MODELLING OF DC MOTOR}

The purpose of modelling DC motor is approaching its actual DC motor. To include its parameters, it can get the transfer function of DC motor for controlling the position.

Fig.1. DC Motor Model 
Table 1

DC Motor Parameters and Values

\begin{tabular}{|l|l|}
\hline Parameter & Value \\
\hline Armature Voltage $\left(\mathrm{V}_{\mathrm{a}}\right)$ & $220 \mathrm{~V}$ \\
\hline Electrical Inductance $\left(\mathrm{L}_{\mathrm{a}}\right)$ & $0.5 \mathrm{H}$ \\
\hline Electrical Resistance $\left(\mathrm{R}_{\mathrm{a}}\right)$ & $1 \Omega$ \\
\hline Moment of Inertia $(\mathrm{J})$ & $0.01 \mathrm{Kg} \cdot \mathrm{m}^{2}$ \\
\hline Friction Coefficient $(\mathrm{B})$ & $0.1 \mathrm{~N}-\mathrm{m} / \mathrm{rad} / \mathrm{sec}$ \\
\hline Back emf Constant $\left(\mathrm{K}_{\mathrm{b}}\right)$ & $0.01 \mathrm{~V} / \mathrm{rad} / \mathrm{sec}$ \\
\hline Rated speed & $1450 \mathrm{rpm}$ \\
\hline Torque Constant $\left(\mathrm{K}_{\mathrm{t}}\right)$ & $0.01 \mathrm{~N} . \mathrm{m} / \mathrm{A}$ \\
\hline
\end{tabular}

By using the above parameters mathematical calculation of transfer function is given as.

$$
\frac{W(s)}{V_{a}(s)}=\frac{K_{t}}{\left.\left(J L_{a} s^{2}+\left(J R_{a}+B L_{a}\right) s+\left(K_{t} K_{b}\right)+B R_{a}\right)\right)}
$$

Substitute the above parameter values in equation 9 transfer finction is obtained as.

$$
\mathrm{Q}(\mathrm{s})=\frac{0.01}{0.005 s^{2}+0.055 s+0.0901}
$$

\section{IV.MODELLING OF DC SERVO MOTOR}

DC servomotors are most preferable in extensive range of speed control and are used for most variable speed control drives. In this model, Fig. 3. represents the DC servomotor model and Fig. 4. Represents schematic diagram of DC servomotor model [1].

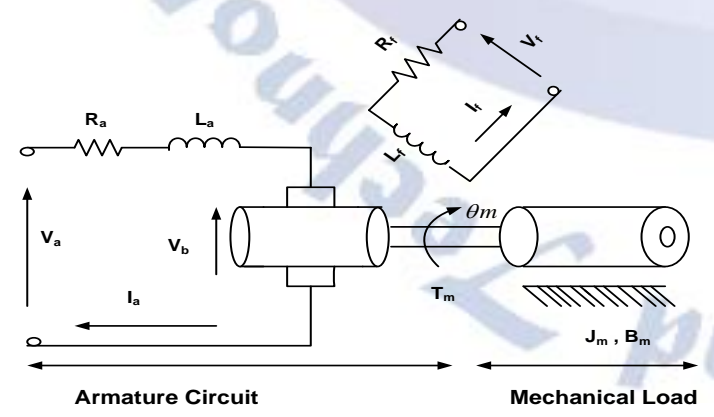

Fig.3. DC Servomotor model

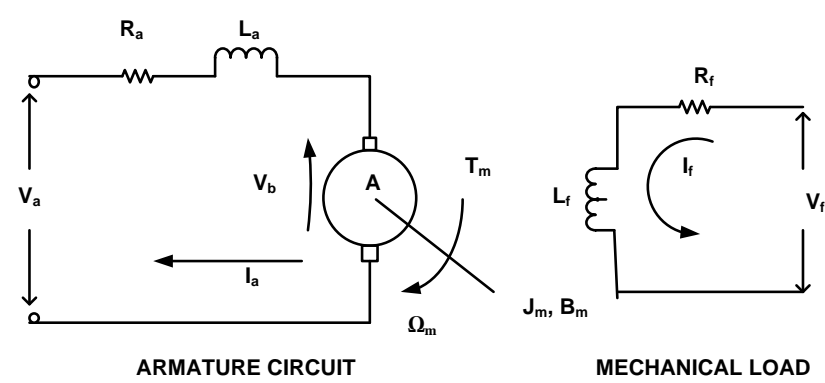

Fig.4. Schematic diagram of DC Servomotor.

Input voltage in Laplace transform is

$$
\begin{aligned}
& E_{a}(s)=L . s . I_{a}(s)+R_{a} \cdot I_{a}(s)+E_{b}(s) \\
& E_{a}(s)=\left(L . s+R_{a}\right) \cdot I_{a}(s)+E_{b}(s)
\end{aligned}
$$

Equation for output mechanical system is

$$
T(t)=J_{m} \cdot \frac{d w_{m}(t)}{d t}+B_{m} \cdot w_{m}(t)
$$

Apply Laplace transform to above equation 3

$$
\begin{gathered}
T(s)=\left[J_{m} \cdot s+B_{m}\right] \cdot \Omega_{m}(s) \\
\Omega_{m}(s)=\left[\frac{1}{J_{m} \cdot s+B_{m}}\right] \cdot T(s)
\end{gathered}
$$

So, the relation between speed of rotor shaft and armature voltage which is applied is represented as transfer function of DC servomotor.

$$
\frac{W(s)}{V_{a}(s)}=\frac{K_{t}}{S\left(J R_{a}+R_{a} B+J L_{a} s^{2}+B L_{a} S+\left(K_{t} K_{b}\right)\right.}(6)
$$

The block diagram of DC servomotor is shown in Fig. 4. with load torque at zero value $\left(T_{L}\right)$.

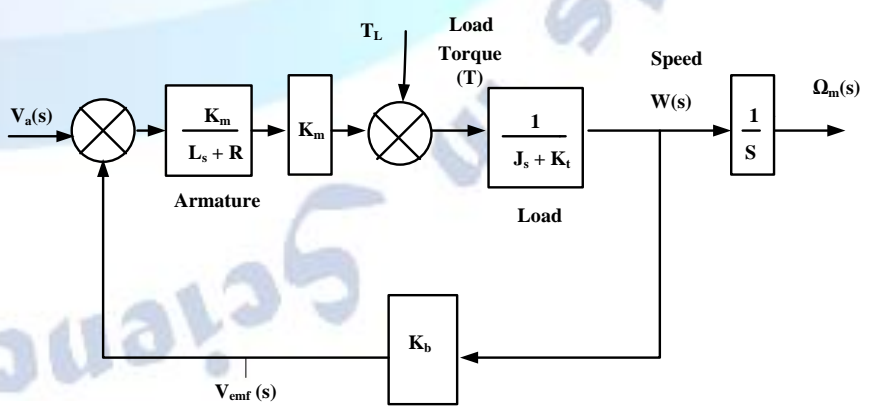

Fig.5. Block diagram of DC Servomotor

\section{V.CONTROL TECHNIQUES COMPARISON}

\section{A. PI Controller}

The Proportional plus Integral controller which provides output signal of two terms : one is 
Proportional to error signal and the other one is Proportional to the Integral of error signal [3]. Fig.5. represents the Simulink model of PI Controller of DC Servomotor.

The one more advantage of PI controller is zero steady state error, Stability and maximum peak overshoot which is better than Integral only controller. PI controller is not suitable to slow moving process variables. Majority of speed control applications are used as PI control actions.

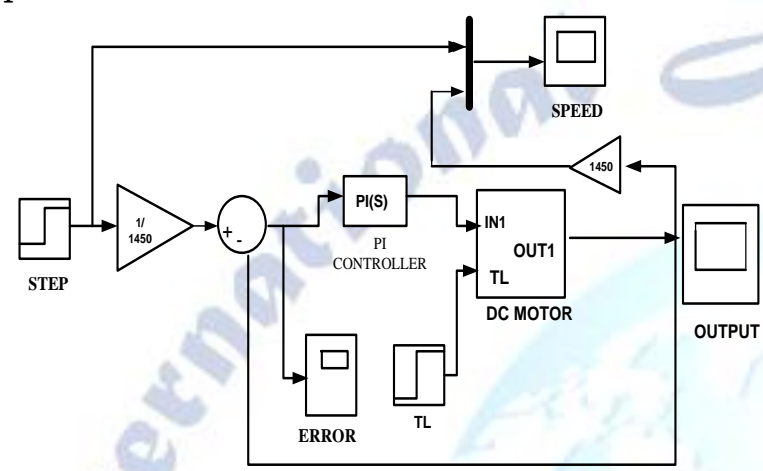

Fig.6. Simulink model of PI controller using DC



Fig.7. Unit step response of PI controller using DC motor

In this simulation result, it is observed that PI controller provides stability to the system, it has higher rise time and settling time. Larger settling time takes high fault currents which takes place in the system. But it has no oscillations.

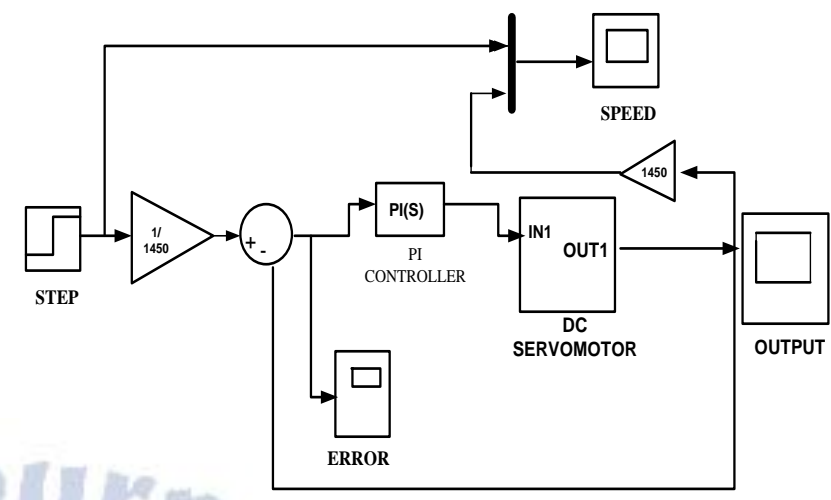

Fig.8. Simulink model of PI Controller using DC Servomotor

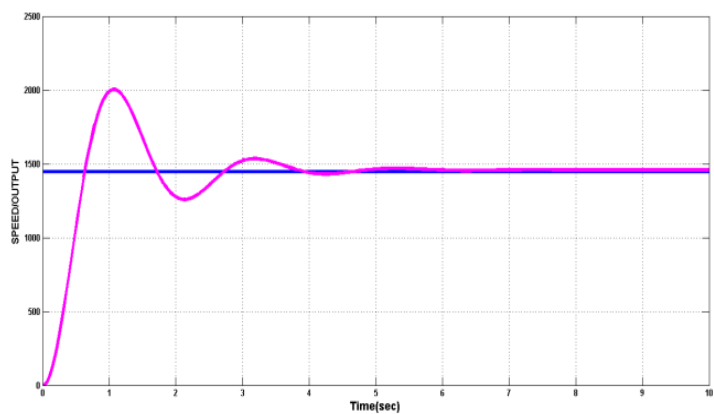

Fig.9. Unit step response of PI controller using DC servomotor

In this simulation result, it is observed that the PI controller provided better stability to the system, and it fully eliminates the steady state error that is offset, good transient response. But it has moderate oscillations and high starting overshoot compared to DC motor.

\section{B. PID controller}

The combination of Proportional plus Integral and Derivative can improve all its parameters of the system performance[3]. Fig.9 represents simulink model of PID controller of DC motor.

The Proportional controller which stabilize the gain but produces steady state error. Integral controller decreases or eliminates steady state error. The Derivative controller reduces the rate of change of error. Fig.11 represents unit step response of DC Servomotor using PID controller [5]. 


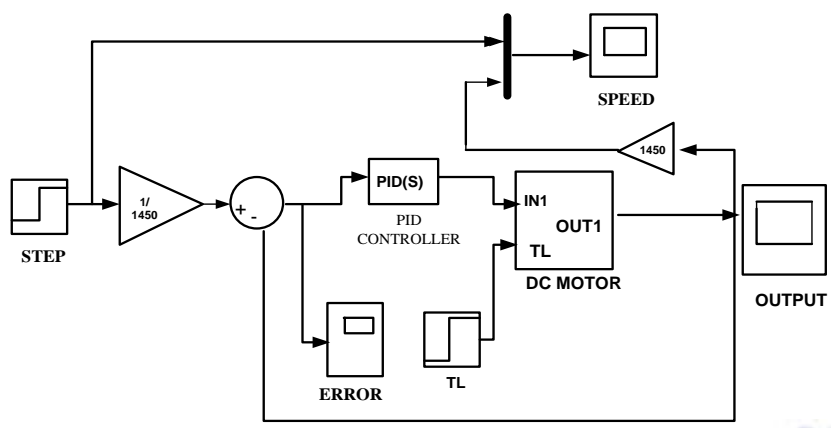

Fig. 10. Simulink model of PID controller using DC motor.

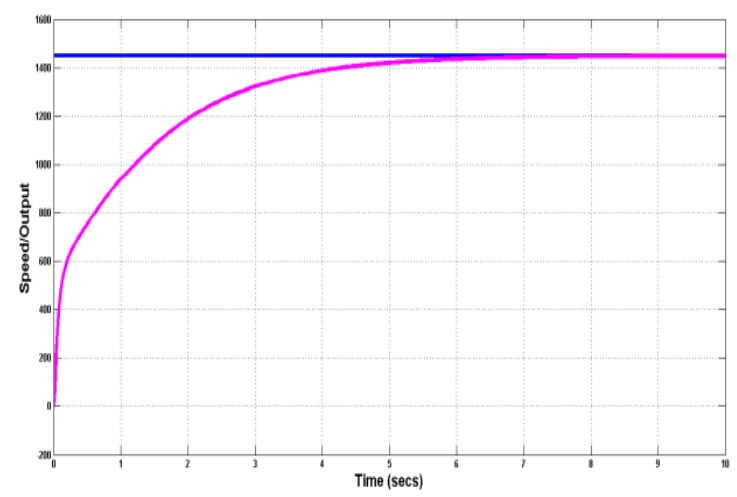

Fig.11. Unit step response of PID controller using DC motor.

This simulation result, it takes more for settling time and rise time. But has no oscillations.

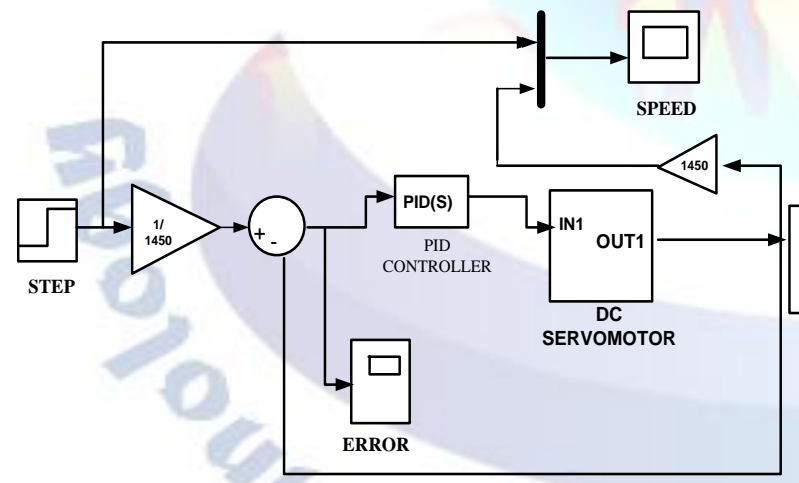

Fig.12. Simulink model of PID Controller using DC Servomotor

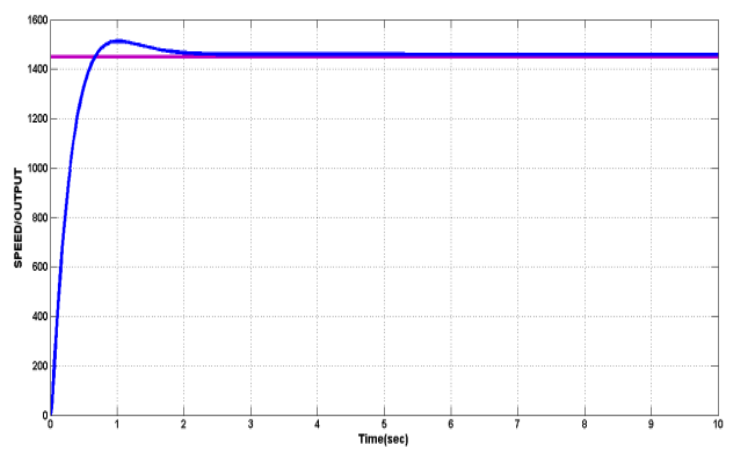

Fig.13. Unit step response of PID Controller using DC servomotor.

Comparing the above two results PID has no oscillations but has faster settling time, reduces peak overshoot. Now a days, PID Controllers are widely used in industrial applications.

The purpose of modeling DC servomotor is approaching actual DC servomotor. Including the parameters, can get the transfer function of DC servomotor for controlling position.

\section{Table 2}

\section{Servomotor Parameters and Values}

\begin{tabular}{|l|l|}
\hline Parameter & Value \\
\hline Armature Voltage $\left(\mathrm{V}_{\mathrm{a}}\right)$ & $220 \mathrm{~V}$ \\
\hline Electrical Inductance $\left(\mathrm{L}_{\mathrm{a}}\right)$ & $0.5 \mathrm{H}$ \\
\hline Electrical Resistance $\left(\mathrm{R}_{\mathrm{a}}\right)$ & $1 \Omega$ \\
\hline Moment of Inertia $(\mathrm{J})$ & $0.01 \mathrm{Kg} \cdot \mathrm{m}^{2}$ \\
\hline Friction Coefficient $(\mathrm{B})$ & $0.1 \mathrm{~N}-\mathrm{m} / \mathrm{rad} / \mathrm{sec}$ \\
\hline Back emf Constant $\left(\mathrm{K}_{\mathrm{b}}\right)$ & $0.01 \mathrm{~V} / \mathrm{rad} / \mathrm{sec}$ \\
\hline Rated speed & $1450 \mathrm{rpm}$ \\
\hline Torque Constant $\left(\mathrm{K}_{\mathrm{t}}\right)$ & $0.01 \mathrm{~N} \cdot \mathrm{m} / \mathrm{A}$ \\
\hline
\end{tabular}

By using the above parameters mathematical calculation in transfer function we can get equation. Here higher order terms are eliminated.

$$
\frac{W(s)}{V_{a}(s)}=\frac{K_{t}}{\left.\left(U L_{a} s^{2}+\left(J R_{a}+B L_{a}\right) s+\left(K_{t} K_{b}\right)+B R_{a}\right)\right)}
$$

Substitute the parameter values in above equation gives

$$
\mathrm{Q}(\mathrm{s})=\frac{0.01}{0.06 s^{2}+0.01 s+0.0001}
$$




\section{C.ZIEGLER - NICHOLOS CONTROLLER}

The Ziegler-Nichols rule is a problem solving PID tuning method that attempts to produce good values for PID gain parameters[5]. Fig.13 represents block diagram of Ziegler-Nicholos controller of DC Servomotor.

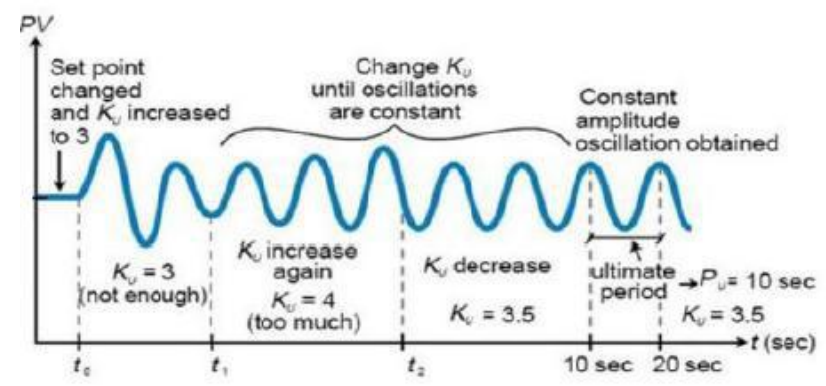

Fig.14. Ziegler - Nichols Controller method.

It is performed by setting the value I (integral) and $\mathrm{D}$ (derivative) gains to zero. The $\mathrm{P}$ (proportional) gain, $\mathrm{K}_{\mathrm{P}}$ is increased from zero to its maximum gain $K_{u}$, which is larger gain at the output of control loop to stable and consistent oscillations. Higher gains than the maximum gain $\mathrm{K}_{\mathrm{u}}$ have diverging oscillations $\mathrm{K}_{\mathrm{u}}$ and the oscillation period $\mathrm{T}_{\mathrm{u}}$ are used to set the $\mathrm{P}, \mathrm{I}, \mathrm{D}$ gains depending on type of controller.

From the result, the complete process depends on two variables and the other systematize parameters are determined according to the table. Fig. 8 represents speed response of DC Servomotor using Ziegler-Nichols method.

\begin{tabular}{|l|l|l|l|}
\hline Type of controller & $K_{\mathrm{p}}$ & $T_{\mathrm{i}}$ & $T_{\mathrm{d}}$ \\
\hline $\mathrm{P}$ & $0.5 K_{\mathrm{cr}}$ & $\infty$ & 0 \\
\hline PI & $0.45 \mathrm{~K}_{\mathrm{cr}}$ & $11.2 P_{\mathrm{cr}}$ & 0 \\
\hline PID & $0.6 K_{\mathrm{cr}}$ & $0.5 P_{\mathrm{cr}}$ & $0.125 P_{\mathrm{cr}}$ \\
\hline
\end{tabular}

Where $\quad K_{p}$ - Path Gain of controller.

$\mathrm{T}_{\mathrm{i}}$ - Integrator time constant.

$\mathrm{T}_{\mathrm{d}}$-Derivative time constant.

From closed loop equation method, $\mathrm{K}_{\mathrm{c}}=13$ and $\mathrm{T}=$ $2 \mathrm{sec}$, that is $\mathrm{K}_{\mathrm{p}}=7.8, \mathrm{~T}_{\mathrm{i}}=1 \mathrm{sec}$ and $\mathrm{T}_{\mathrm{d}}=0.5$.

In this method DC motor transfer function is used as

$$
\mathrm{Q}(\mathrm{s})=\frac{0.01}{0.005 s^{2}+0.055 s+0.0901}
$$

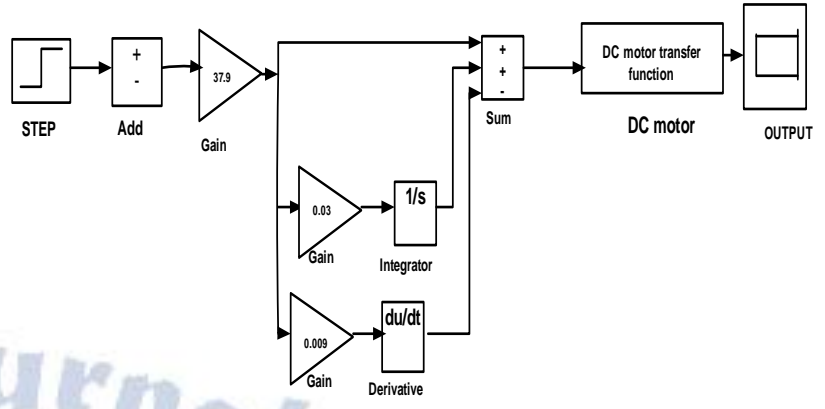

Fig.15. Simulink model of Ziegler-Nicholas Controller of DC motor.

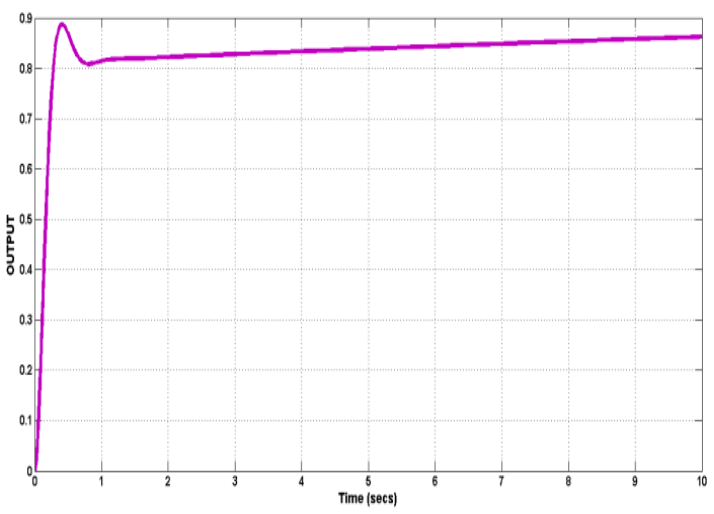

Fig.16. Ziegler-Nichols Controller-Speed response of DC motor.

Comparing the DC motor results of PI and PID controllers, ZNM has faster rise time and settling time and has no peak overshoot.

For this method DC servomotor transfer function is used

$$
\mathrm{Q}(\mathrm{s})=\frac{0.01}{0.06 s^{2}+0.01 s+0.0001}
$$

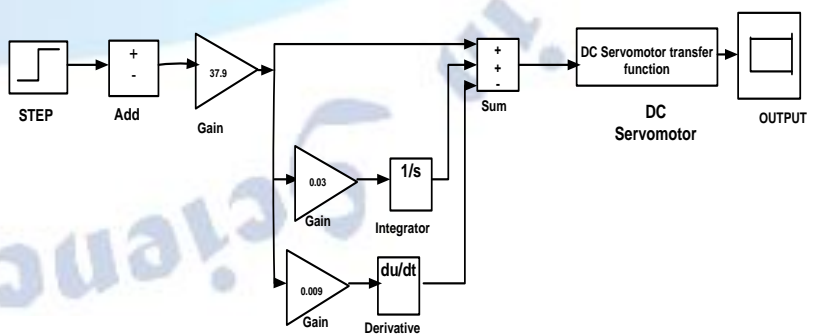

Fig.17. Simulink model of Ziegler-Nicholas Controller of DC Servomotor 


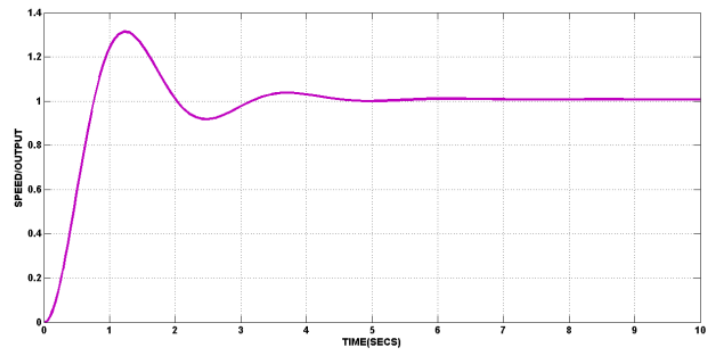

Fig.18. Ziegler-Nichols Controller Speed response of DC Servomotor

From above simulation result of Ziegler Nichols methods of DC servomotor has all the parameters are controlled compared to PI and PID controllers but has moderate oscillations occurred.

\section{D.INTERNAL MODE CONTROL (IMC)}

The theory of IMC states that "control can be achieved only if the control system encapsulates, either implicitly or explicitly, some representation of the process to be controlled" [5].

The IMC (Internal Mode Control) controller is based on the inverse of the process model and the gain becomes unity and have a perfect set-point tracking.

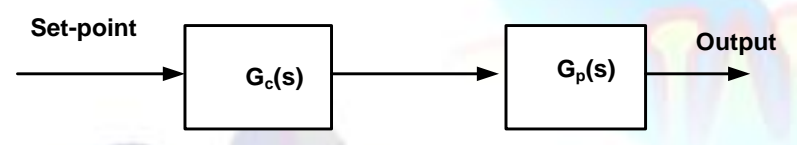

Fig.19. Equivalent block diagram of IMC

$$
G_{c}(s)=\frac{Q(s)}{1-\widetilde{G p}(s) \cdot Q(s)}
$$

Now,

$$
\mathrm{G}_{\mathrm{P}}(\mathrm{s})=\widetilde{G p}(s)
$$

Designed the IMC controller

$$
\begin{aligned}
& \mathrm{G}_{\mathrm{IMC}}=\mathrm{Q}(\mathrm{s})=[\widetilde{G p}(s)]^{-1} \mathrm{G}_{\mathrm{f}}(\mathrm{s}) \\
& \widetilde{G p}(s)=1-\mathrm{G}_{\mathrm{p}}(\mathrm{s})
\end{aligned}
$$

Where $G_{f}(s)$ is a low pass function defined as

$$
\mathrm{G}_{\mathrm{f}}(\mathrm{s})=\frac{1}{(1+\propto s)^{\wedge} n}
$$

Now the DC moor transfer equation is

$$
\frac{W(s)}{V_{a}(s)}=\frac{K_{t}}{\left.\left(J L_{a} s^{2}+\left(J R_{a}+B L_{a}\right) s+\left(K_{t} K_{b}\right)+B R_{a}\right)\right)}
$$

Taking $\mathrm{a}=0.9$ and $\mathrm{n}=2$ for second order low pass filter.

So finally the equation becomes

$$
G_{c}(s)=\frac{Q(s)}{1-\widetilde{G p}(s) \cdot Q(s)}
$$

Substitutute equations 4 and 5 in 6 using the DC motor parameters and values, low pass filter value in above equation we can get equation as follows

$$
\mathrm{Q}(\mathrm{s})=\frac{0.006 s^{2}+0.030 s+0.0801}{0.005 s^{2}+0.055 s+0.0901}(8)
$$

Simply IMC is nothing but tuning of PID or transfer function of the motor.IMC is tuning with PID along with DC servomotor then we can get better result from above methods.

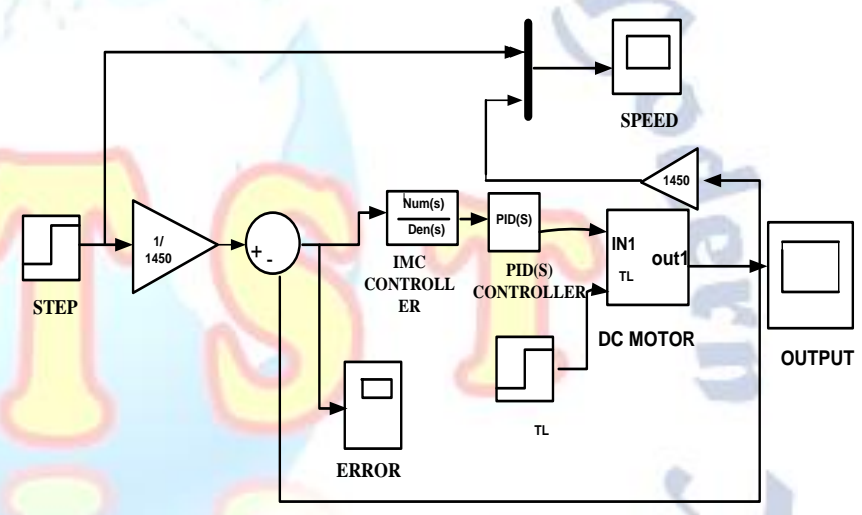

Fig. 20. Simulink model of IMC -PID controller using DC motor

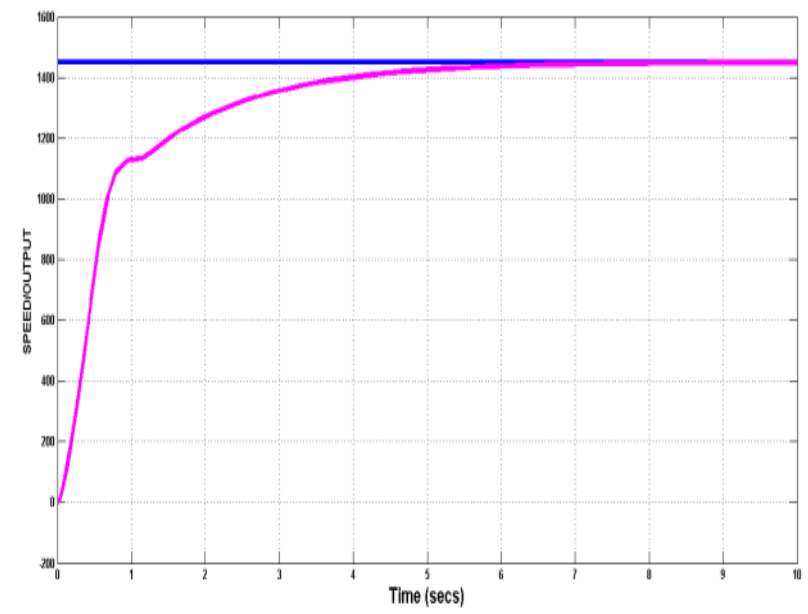

Fig.21. Unit step response of IMC controller of DC motor.

In this IMC-PID based DC motor we observed faster settling time, rise time and has no oscillation and absence of peak overshoot. 
In the same manner, for IMC=PID design can be used to DC servomotor

The transfer function of DC servomotor is

$$
\frac{W(s)}{V_{a}(s)}=\frac{K_{t}}{S\left(J R_{a}+R_{a} B+J L_{a} s^{2}+B L_{a} S+\left(K_{t} K_{b}\right)\right.}(6)
$$

Substitutute equations 4 and 5 in 9 using the DC servomotor parameters and values, low pass filter value in above equation we can get equation as follows

$\mathrm{Q}(\mathrm{s})=\frac{0.06 s^{2}+0.010 s+0.0001}{0.06 s^{2}+0.01 s+0.0008}$

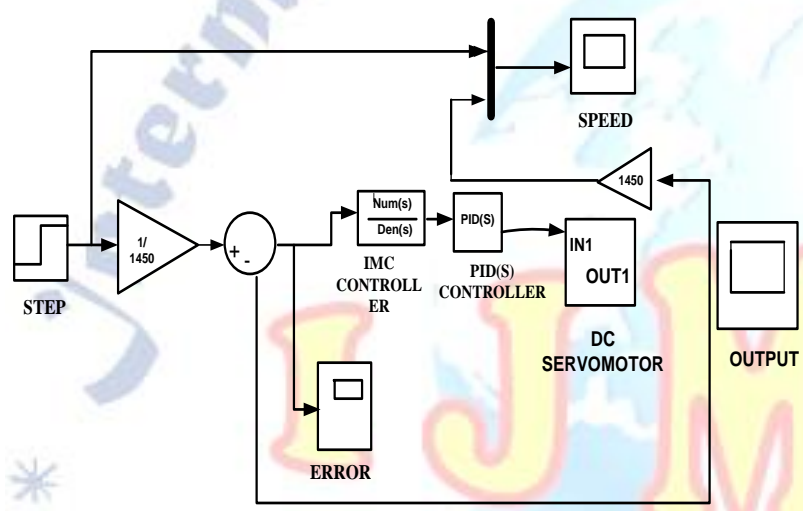

Fig.22. Simulink model of IMC-PID controller using DC servomotor.

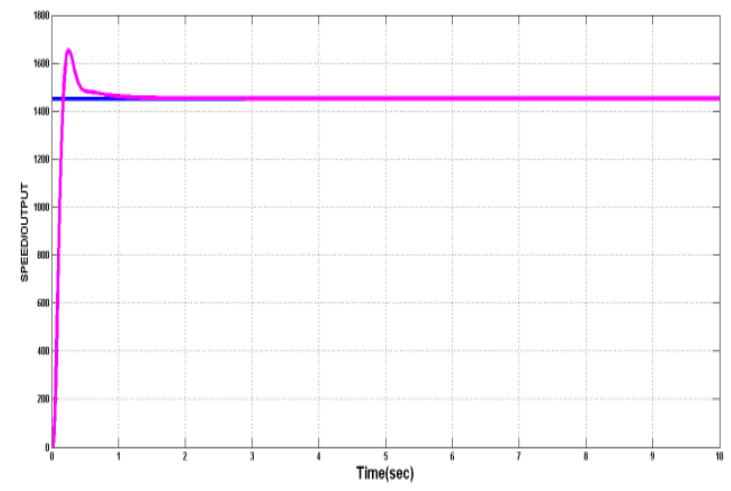

Fig.23. Unit step response of IMC-PID controller using DC servomotor.

Comparing all the results, of DC motor and DC servomotor IMC based PID gives better result like rise time, settling time, peak overshoot and absence of oscillations.

\section{VI.RESULTS}

On comparing speed control of DC motor and DC servomotor wit different controllers under same parameters gives better result are as table follows.

Comparing all the conventional controller like PI, PID, Ziegler Nichols method, IMC-PID controllers of DC motor and DC servomotor gives various results under same time domain parameters and gives results as rise time, settling time, overshoot, peak amplitude and oscillations.

Apart from IMC based PID controller of DC servomotor, none of the controller controls the whole parameters.

The final result are as follows in terms of time domain specifications are rise time as 0.3 secs, settling time as 1.0, speed for peak amplitude as $1450 \mathrm{rpm}$, peak overshoot is 1.0 with absence of oscillations.

\begin{tabular}{|c|c|c|c|c|c|c|}
\hline Motor & $\begin{array}{l}\text { contr } \\
\text { oller }\end{array}$ & $\begin{array}{l}\text { Rise } \\
\text { tim } \\
\mathrm{e} \\
\left(\mathrm{T}_{\mathrm{R})}\right.\end{array}$ & $\begin{array}{l}\text { Settli } \\
\text { ng } \\
\text { time } \\
\left(T_{\mathrm{s}}\right)\end{array}$ & Speed & $\begin{array}{l}\text { Peak } \\
\text { amplit } \\
\text { ude }\end{array}$ & $\begin{array}{l}\text { oscillation } \\
\mathrm{s}\end{array}$ \\
\hline $\begin{array}{l}\text { DC } \\
\text { motor }\end{array}$ & PI & 7.2 & 9.3 & 1450 & 1.1 & no \\
\hline $\begin{array}{l}\text { DC } \\
\text { servo } \\
\text { motor }\end{array}$ & PI & 0.8 & 6.0 & 1450 & 1.22 & moderate \\
\hline $\begin{array}{l}\text { DC } \\
\text { motor }\end{array}$ & PID & 6.9 & 8.5 & 1450 & 1.1 & no \\
\hline $\begin{array}{l}\text { DC } \\
\text { servo } \\
\text { motor }\end{array}$ & PID & 0.7 & 5.0 & 1450 & 1.1 & no \\
\hline $\begin{array}{l}\mathrm{DC} \\
\text { motor }\end{array}$ & ZNM & 0.9 & 9.0 & 1450 & 1.3 & no \\
\hline $\begin{array}{l}\text { DC } \\
\text { servo } \\
\text { motor }\end{array}$ & ZNM & 1.3 & 5.0 & 1450 & 1.1 & moderate \\
\hline $\begin{array}{l}\mathrm{DC} \\
\text { motor }\end{array}$ & $\begin{array}{l}\text { IMC-P } \\
\text { ID }\end{array}$ & 0.6 & 2.0 & 1450 & 1.1 & no \\
\hline $\begin{array}{l}\mathrm{DC} \\
\text { servo } \\
\text { motor }\end{array}$ & $\begin{array}{l}\text { IMC-P } \\
\text { ID }\end{array}$ & 0.3 & 1.0 & 1450 & 1.0 & no \\
\hline
\end{tabular}

\section{VI.CONCLUSION}

In this work, Speed control of DC motor and DC Servomotor is controlled by different conventional controllers method under same parameters gives better performance, on which IMC-PID controller of 
DC Servomotor gives better results comparison is shown here in terms of time domain specifications such as rise time 0.3 seconds, settling time 1 second, speed with peak overshoot $1450 \mathrm{rpm}$, peak amplitude 1.0 and absence of oscillations. Apart from IMC based PID controller of DC servomotor, none of the controller controls the whole parameters.

\section{VII.REFERENCES}

1. Toe Toe Hlaing, "Simulation of Ziegler-Nichols PID Tuning for position control of DC servomotor", International Journal of Scientific and Research Publications, Volume no 9, Issue 7, July 2019.

2. B Munadi and M. Amirullah Akbar "Simulation of Fuzzy Logic Control for DC servomotor using Aurdino based on Matlab/Simulink", International Conference on Intelligent Autonomous Agents, Networks and Systems, 2014.

3. Mahir Dursun and Ahmet Fenercioğlu, "An educational tool for DC motor PID speed controller", Scientific research and essays, September 2011.

4. G. Vasudevarao and V. Rangavalli,

"Comparison of Speed Control of DC servomotor using PI, PID, Fuzzy, SMC", International Advanced Research Journal in Science, Engineering and Technology, November 2016.

5. Md Akram Ahmad, Kamal Kishor and Pankaj Rai, "Speed control of a DC motor using Controllers", Automation, Control and Intelligent Systems, 2014.

6. M.Saranya and D.Pamela, "A Real Time IMC Tuned PID Controller for DC Motor", International Journal of Recent Technology and Engineering, ISSN: 2277-3878, Volume 1, Issue-1, April 2012.

7. K.Venkateswarlu and Ch. Chengaiah, "Comparative study on DC motor speed control using various controllers", Volume 1, Issue 6 Dec 2013.

8. Kiam Heong Ang, Gregory Chong and Yun Li, "PID Control System Analysis, Design, and Technology”, IEEE Trans., Control System and Technology, vol. 13, no. 4, pp. 559-576, Ju12005.

9. Zhicheng Zhao, Jianggang Zhang and Mingdong Hou, "An adaptive IMC-PID control scheme based on neural network", presented at the IEEE conference, 2009.

10. Katsuhiko Ogata, "Modern Control Engineering", $5^{\text {th }}$ edition , 2010.

11. Zadeh., L.A., "Fuzzy Sets", Information and Control, vol. 8, pp.338-353, 1965.

12. Alok Ranjan Singh and V.K. Giri., "Design and Analysis of DC Motor Speed Control by GA Based Tuning of Fuzzy Logic Controller", International Journal of Engineering Research \& Technology (IJERT), Vol. 1, Issue $5^{\text {th }}$ July 2012.

13. Alok Ranjan Singh and V.K. Giri., "Compare and simulation of speed control of DC motor using PID and Fuzzy controller", VSRD International Journal of Electrical and Electronics \& Communication Engineering, Volume 2, 10 October 2012.

14. Larsen P.M., "Industrial application of Fuzzy LogicControl", Academic press, inc., may, 1979.

15. Zadeh, L.A., "Fuzzy relation Equations and Applications to Knowledge Engineering", Kluwer Academic Publishers, Holland, 1989. 